\title{
ANALISIS PENGARUH KEMUDAHAN, KENYAMANAN DAN EFISIENSI TERHADAP FREKWENSI PEMBELIAN PRODUK MELALUI INTERNET
}

OLEH

AGUS WISMO WIDODO

UNIVERSITAS PERSADA INDONESIA YAI

JAKARTA 2019 


\section{ABTRAKSI}

Tulisan ini merupakan hasil penelitian untuk mengungkap tentang faktor-faktor yang berpengaruh terhadap prilaku konsumen dalam membeli produk melalui internet.

Penelitian ini bertolak dari adanya pergeseran prilaku belanja oleh sebagian anggota masyarakat, dimana membeli produk melalui internet sebelumnya hanya dilakukan oleh masyarakat yang menguasai Teknologi Informasi ataupun kalangan atas.

Oleh karena itu tujuan penelitian ini untuk mengetahui Prilaku konsumen dalam memutuskan untuk membeli produk melalui internet, Faktor-faktor yang berpengaruh terhadap pembelian produk melalui internet serta Pengaruh antara faktor-faktor kemudahan, kenyamanan dan effisiensi dalam membeli produk melalui internet dengan prilaku konsumen.

Penelitian dilaksanakan menggunakan metode survey. Populasi responden adalah seluruh konsumen yang membeli produk melalui internet. Sebanyak 125 responden diambil sampel dengan menggunakan teknik Acendetal Sampling.

Dalam menentukan responden, penulis membegi karakteristik responden menjadi 3 katagori, yaitu konsumen yang berusia antara 15-25 tahun, responden yang kedua berusia antara 26-35 tahun serta responden yang diatas 35 tahun.

Dari sisi pkerjaan, penulis juga membagi responden menjadi 3 kategori, yaitu responden yang bekerja sebagai pegawai, sebagai wiraswasta maupun responden yang berstatus mahasiswa. 
Untuk jumlah penghasilan, penulis mengelompokkan responden yang berpenghasilan antara Rp. 1,000,000 sampai Rp. 5.000.000, yang berpenghasilan 515 jutq, serta yang berpenghsiilan diatas Rp.15.000 .000.

Pengumpulan data dilakukan dengan menggunakan daftar pertanyaan.Analisis data menggunakan teknik scoring, untuk mengkwantifikasi data kwalitatif.

Hasil penelitian menunjukkan bahwa persepsi konsumen terhadap pembelian produk melalui internet secara umum menunjukkan persepsi yang positif, walaupun skor rata-rata yang tidak cukup tinggi. Secara umum tidak terdapat pengaruh yang kuat dari segi social ekonomi konsumen terhadap persepsi konsumen. Baik mengenai kenyamanan, kemudahan dan effisiensi dalam membeli produk melalui internet. Dengan demikian dapat disimpulkan bahwa semakin tinggi tingkat persepsi baik terhadap kemudahan belanja melalui internet, effisiensi waktu dan biaya, kenyamanan belanja maka seseorang akan semakin sering melakukan pembelian produk melalui internet, 


\section{BAB I}

\section{PENDAHULUAN}

\subsection{Latar belakang penulisan.}

Demam internet telah melanda dunia. Jika beberapa tahun lalu hanya Negara Negara maju saja yang menjadikan internet sebagai gaya hidup, sekarang hampir diseluruh belahan dunia sudah menjadikan internet sebagai gaya hidup baru yang mempengaruhi pola hidup banyak orang.

Perkembangan Teknologi Informasi tampaknya berjalan demikian cepat, bahkan lebih cepat dari yang dibayangkan. Dalam kurun lima tahun terakhir penggunaan perangkat komputer maupun Handphone guna menunjang aktivitas bisnis semakin meningkat. Ini semua tak lain karena perkembangan teknologi global yang menuntut setiap pelaku bisnis untuk menyesuaikannya. Belakangan, transaksi bisnis yang menggunakan jasa internet tumbuh semakin subur.

Dengan adanya perubahan yang sedemikian cepat itu membuat bidang pemasaran menjadi sangat dinamis. Transaksi bisnis dengan melakukan pertemuan di suatu tempat atau bertatap muka langsung tampatknya akan ditinggalkan. Cara bisnis seperti akan digantikan hanya dengan seperangkat komputer dengan fasilitas internet. Dimanapun si pelaku bisnis berada tetap dapat melakukan transaksi bisnis melalui notebook ataupun handphone yang mudah dibawa kemana mana.

Perdagangan diatas teknologi Internet yang lebih dikenal dengan istilah ECommerce akhir-akhir ini sudah semakin marak dengan bermunculannya 
ribuan perusahaan yang menawarkan barang dagangannya diatas website.Melalui E-Commerce transaksi bisnis tidak lagi mengenal jarak geografis. Semua bias dilakukan melalui layar monitor computer maupun Hp. Transaksi bias diakukan kapan saja dan dimana saja.

Semua kelebihan dan keunggulan yang ditampilkan E-Commerce ini menunjukkan adanya peluang pasar yang terdapat pada komunitas internet. Pasar yang demikian besar tersebut sangatlah sayang dilewatkan begitu saja. Transaksi E-Commerce bisa dilakukan melalui Email, Facebook, Instagram atau program aplikasi yang lain untuk memesan barang. Begitu transaksi pembayaran barang disetujui, barang akan dikirim kepada pemesan.

\section{I.2. Rumusan masalah}

Penelitian ini bertolak dari adanya pergeseran prilaku belanja melalui internet oleh sebagian masyarakat di Indonesia, dimana belanja melalui internet sebelumnya hanya dilakukan oleh masyarakat tertentu saja yang menguasai teknologi ataupun masyarakat yang mempunyai golongan ekonomi tingkat atas, tetapi saat ini pembelian produk melalui internet sudah merupakan hal yang biasa dan disukai oleh sebagian masyarakat. Kenyataan tersebut menimbulkan pertanyaan bagi penulis sebagai berikut : 
Bagaimana pengaruh faktor-faktor kemudahan, kenyamanan dan effisiensi terhadap frekwensi pembelian produk melalui Internet?

\section{I.3 TUJUAN PENULISAN}

Sejalan dengan permasalahan penelitian diatas, maka tujuan penelitian ini diarahkan untuk mengetahui pengaruh faktor-faktor kemudahan, kenyamanan dan effisiensi terhadap frekwensi pembelian produk melalui internet.

\section{I.4 MANFAAT PENULISAN}

Melalui penelitian ini manfaat yang diharapkan adalah sebagai berikut :

1. Bagi perusahaan, dapat memberi informasi dalam penyusunan strategi pemasaran agar mampu bersaing menghadapi pasar global.

2. Bagi Akademik, Untuk dapat dikembangkan mengingat E-commerce adalah sesuatu yang masih perlu digali dan dipelajari. Disamping itu juga akan dapat menunjang bagi pengembangan teknologi Informasi.

3. Bagi Masyarkat, dapat memahami mengenai keuntungan bertransaksi melalui internet. 
BAB II

\section{LANDASAN TEORI}

\section{II.1 Pengertian E-Commerce}

Pemasaran merupakan salah satu dari kegiatan utama yang dilakukan oleh pengusaha dalam usahanya untuk kelangsungan hidup perusahaan. Dengan adanya persaingan bisnis yang semakin tajam dan keinginan konsumen yang semakin beragam maka selalin diperlukan promosi yang efektif juga diperlukan pemanfaatan teknologi, khususnya pemanfaatan teknologi internet agar dapat memenangkan persaingan bisnis.

Transaksi perdagangan diatas internet yang lebih dikenal dengan sebutan E-Commerce adalah istilah yang digunakan untuk penawaran, pembelian sampai dengan pengiriman barang atau jasa melalui jalur internet, sedangkan cara pembayarannya bisa dilakukan dengan menggunakan kartu kredit ataupun uang tunai.

E-Commerce merupakan satu set dinamis teknologi. Aplikasi dan proses bisnis menghubungkan perusahaan, konsumen dan komunitas tertentu melalui proses elektronik dan perdagangan barang, pelayanan dan informasi yang dilakukan secara elektronik (David Baum, 1999:36)

Pengertian pemasaran modern berdasarkan pendapat diatas, dapat disintesiskan bahwa pemasaran mencangkup usaha pemasaran yang dimulai dengan mengidentifikasikan kebutuhan konsumen yang perlu dipenuhi, menentukan produk yang sesuai, menentukan cara-cara promosi 
dan distribusi produk tersebut. Dengan demikian dapat dikemukakan bahwa kegiatan pemasaran adalah kegiatan yang saling berhubungan sebagai suatu sistem.

II.2 Tahap-tahap dalam proses keputusan membeli

Prilaku konsumen akan menentukan proses pengambilan keputusan

dalam pembelian mereka.Proses tersebut merupakan sebuah pendekatan

penyelesaian masalah yang terdiri atas lima tahap :

a. Menganalisa keinginan dan kebutuhan terutama di tujukan untuk mengetahui adanya keinginan dan kebetuhan yang belum terpenuhi atau terpuaskan.

b. Pencarian Informasi dan Penilaian Sumber-sumber pembelian dapat berasal dari komunikasi perorangan dan pengaruh perorangan, yang terutama dari pelopor opini. Informasi eksternal didapat dari media dan sumber informasi dari kegiatan pemasaran perusahaan.

c. Penilaian dan seleksi terhadap alternative pembelian, yaitu menetapkan tujuan penilai dan menilai serta mengadakan seleksi terhadap alternative pembelian berdasarkan tujuan pembeliannya.

d. Keputusan pembelian, maka serangkaian keputusan yang akan diambil adalah tentang jenis produk, bentuk produk, merk, kualitas dan waktu pembayaran serta cara pembayaran. 


\section{BAB III}

\section{PEMBAHASAN}

\section{III-1 KARAKTERISTIK RESPONDENCE E-COMMERCE}

TABEL III-1 : Karakteristik Responden menurut Jenis Kelamin

\begin{tabular}{|l|c|c|c|c|c|}
\hline JENIS & & & & & \\
KELAMIN & KEMUDAHAN & KENYAMANAN & EFFISIEN & JUMLAH & PERSEN \\
\hline PRIA & 13 & 26 & 42 & 81 & $64.8 \%$ \\
\hline WANITA & 12 & 16 & 16 & 44 & $35.2 \%$ \\
\hline JUMLAH & 25 & 42 & 58 & 125 & $100 \%$ \\
& $20 \%$ & $33.6 \%$ & $46,4 \%$ & $100 \%$ & \\
\hline
\end{tabular}

Suber : Kuesioner dengan 125 Responden.

Hasil penelitian menunjukkan bahwa sebagian besar responden E-Commerce (64.8\%) adalah pria dan 35,2 \% adalah wanita. Perbedaan tersebut nampaknya berkaitan erat dengan perbedaan sifat dasar antara pria dan wanita, dimana sifat pria pada umumnya lebih banyak yang menyukai bidang teknologi dan selalu ingin mengetahui hal-hal yang baru. Sedangkan sifat dasar wanita lebih sedikit yang berminat di bidang teknologi. Perbedaan sifat dasar inilah berkaitan pada proporsi konsumen pria lebih banyak dibandingkan dengan konsumen wanita.Namun demikian dengan semakin majunya perkembangan teknologi dan kesamaan hak antara pria dan wanita, memungkinkan proporsi tersebut akan sama dimasa mendatang.

TABEL III-2 : Karakteristik Responden menurut Usia

\begin{tabular}{|l|c|c|c|c|c|}
\hline Usia & & & & & \\
Responden & KEMUDAHAN & KENYAMANAN & EFFISIEN & JUMLAH & PERSEN \\
\hline $15-25$ & 7 & 6 & 11 & 24 & $19,2 \%$ \\
\hline $26-35$ & 18 & 21 & 27 & 66 & $52,8 \%$ \\
\hline$>35$ & 10 & 5 & 20 & 35 & $28 \%$ \\
\hline JUMLAH & 35 & 32 & 58 & 125 & $100 \%$ \\
& $28 \%$ & $25,6 \%$ & $46,4 \%$ & $100 \%$ & \\
\hline
\end{tabular}

Suber : Kuesioner dengan 125 Responden. 
Secara umum konsumen yang berbelanja melalui internet dapat dibedakan menjadi tiga kategori yaitu konsumen antara 15-25 tahun, konsumen yang berusia antara 26-35 tahun dan konsumen yang berusia diatas 35 tahun. Responden konsumen yang berbelanja melalui internet ( $19,2 \%$ ) adalah kaum muda yang berusia antar 15-25 tahun. Mereka umumnya mahasiswa dan para pekerja yang masih meniti karir di pekerjaannya. 52,8\% adalah kaum dewasa yang berusia antara 26-35 tahun. Mereka sebagian besar sudah memiliki pekerjaan tetap dan sudah memiliki karir yang jelas. Sedangkan $28 \%$ konsumen adalah mereka yang berusia diatas 35 tahun yang secara ekonomi sudah baik. Dengan demikian dapat dikemukakan bahwa konsumen pembeli produk melalui internet didominasi oleh kaum dewasa yang berusia antara $26-35$ tahun.

TABEL III-3 : Karakteristik Responden menurut Pekerjaan

\begin{tabular}{|l|c|c|c|c|c|}
\hline Pekerjaan & & & & & \\
& KEMUDAHAN & KENYAMANAN & EFFISIEN & JUMLAH & PERSEN \\
\hline Mahasiswa & 6 & 7 & 9 & 22 & $17,6 \%$ \\
\hline Pegawai & 21 & 25 & 37 & 83 & $66,4 \%$ \\
\hline Wiraswasta & 6 & 6 & 8 & 20 & $16 \%$ \\
\hline JUMLAH & 35 & 32 & 58 & 125 & $100 \%$ \\
& $26,4 \%$ & $30,4 \%$ & $43,2 \%$ & $100 \%$ & \\
\hline
\end{tabular}

Suber : Kuesioner dengan 125 Responden.

Salah satu karakteristik sosial ekonomi konsumen E-Commerce adalah jenis pekerjaan. Dalam satu pekerjaan tertentu sering konsumen memiliki waktu yang terbatas bahkan hampir tidak memiliki waktu luang sedikitpun untuk berbelanja, sehingga pembelian produk melalui internet seringkali mengidentifikasikan kesibukan sesorang. Dalam kaitannya dengan pekerjaan, pembelian produk melalui internet secara umum konsumen pembelian produk melalui internet dibedakan menjadi 3 kategori yaitu Mahasiswa, pegawai dan wiraswasta. Hasil penelitian menunjukkan bahwa berdasarkan jenis pekerjaan konsumen E-Commerce 17,6\% adalah mahasiswa, $66,4 \%$ adalah pegawai dan $16 \%$ adalah wiraswasta. 
TABEL III-4 : Karakteristik Responden menurut Penghasilan

\begin{tabular}{|l|c|c|c|c|c|}
\hline $\begin{array}{l}\text { PENGHASILAN } \\
\text { (dalam ribuan) }\end{array}$ & KEMUDAHAN & KENYAMANAN & EFFISIEN & JUMLAH & PERSEN \\
\hline $1.000-5.000$ & 16 & 12 & 15 & 43 & $34.4 \%$ \\
\hline $5.000-15.000$ & 19 & 10 & 24 & 53 & $42.4 \%$ \\
\hline$>15.000$ & 6 & 7 & 16 & 29 & $23,2 \%$ \\
\hline JUMLAH & 41 & 29 & 55 & 125 & $100 \%$ \\
& $32,8 \%$ & $23,2 \%$ & $44 \%$ & $100 \%$ & \\
\hline
\end{tabular}

Suber : Kuesioner dengan 125 Responden.

Kemampuan konsumen untuk membeli produk melalui internet tergantung pada besarnya penghasilan. Dalam penelitian ini penghasilan dikelompokkan kedalam tiga kategori yaitu penghasilan antara $1.000 .000 \mathrm{sd} 5.000 .000$, penghasilan antara 5.000.000 - 15.000.000 dan penghasilan diatas 15.000.000. Hasil analisis karakteristik konsumen atas dasar pendapatan memperlihatkan bahwa sebagian besar $42,4 \%$ adalah konsumen dengan penghasilan antara 5.000.000 - 15.000.000, sedangkan penghasilan antara $1.000 .000-5.000 .000$ dan diatas 15.000 .000 masing masing sebesar $34,4 \%$ dan $23,2 \%$. 


\section{III-2 Analisa SWOT}

\begin{tabular}{|c|c|}
\hline Kekuatan (Strength) & Kelemahan (Weakness) \\
\hline $\begin{array}{l}\text { 1. Transaksi dapat dilakukan kapan } \\
\text { saja, tidak dibatasi waktu } \\
\text { 2. Tidak perlu meluangkan waktu, } \\
\text { tenaga dan biaya untuk keluar } \\
\text { rumah. } \\
\text { 3. Konsumen dapat membandingkan } \\
\text { harga dengan cepat. }\end{array}$ & $\begin{array}{l}\text { 1. Tidak blsa mencoba } \\
\text { langsung produk yang dibeli } \\
\text { 2. Tidak bias menawar harga } \\
\text { 3. Diperlukan waktu untuk } \\
\text { mengantar barang }\end{array}$ \\
\hline Peluang(Oportunity) & Ancaman (Threat) \\
\hline $\begin{array}{l}\text { 1. Semakin banyak konsumen yang } \\
\text { memakai komputer. } \\
\text { 2. Semakin banyak konsumen yang } \\
\text { memiki Personal Computer (PC) } \\
\text { 3. Semakin sedikitnya konsumen } \\
\text { memiliki waktu luang. }\end{array}$ & $\begin{array}{l}\text { 1. Kemungkinan munculnya } \\
\text { Haecker yang } \\
\text { membayakan proses } \\
\text { transaksi yang } \\
\text { berhubungan dengan } \\
\text { Integrity, Availability dan } \\
\text { legimate use. }\end{array}$ \\
\hline
\end{tabular}




\section{BAB IV}

\section{KESIMPULAN DAN SARAN}

\section{IV-1 Kesimpulan}

Berdasarkan hasil analisis data dan pembahasan yang telah diuraikan sebelumnya, dapat dikemukakan beberapa kesimpulan sebagai berikut :

1. Pengaruh antara Faktor-faktor persepsi terhadap setiap atribut pembelian produk melalui internet dapat dikemukakan sebagai berikut

a. Tidak terdapat hubungan yang positif dan significant antara jenis kelamin dengan frekwensi pembelian produk melalui internet.

b. Terdapat hubungan yang positif dan significant antara factor usia dengan Frekwensi pembelian produk melalui internet.

c. Terdapat hubungan yang positif dan sangat Significant antara jenis pekerjaan dengan Frekwensi pembelian produk melalui internet.

d.Tidak terdapat hubungan yang positif dan significant antara besarnya penghasilan dengan Frekwensi pembelian produk melalui internet.

2. Faktor yang paling berpengaruh terhadap pembelian produk melalui internet adalah Faktor Effisiensi yang dapat dijabarkan sebagai berikut :a. Berdasarkan karakteristik Responden E-Commerce (46,4\%) menurut kategori jenis kelamin dan usia. Faktor Effisiensi adalah factor yang paling berpengaruh dibandingkan dengan faktor kemudahan (20\%) dan kenyamanan (33.6\%).

b.Berdasarkan Karakteristik Responden E-Commerce menurut kategori Jenis pekerjaan Faktor Effisiensi $(43,2 \%)$ merupakan faktor yang paling berpengaruh dibandingkan dengan faktor kemudahan (26,4\%) dan kenyamanan ( $30,4 \%)$. 


\section{IV-2 Saran}

Bertolak dari kenyataan bahwa konsumen yang mempunyai Karakteristik berbeda ternyata mempunyai persepsi dan prilaku yang berbeda, maka produsen perlu memahami lebih jauh hal-hal seperti itu sebagai implikasi pada strategi pemasaran, Beberapa pendapat yang mungkin dapat digunakan sebagai masukan dan bahan pertimbangan dalam penyusunan strategi pemasaran bagi produsen adalah sebagai berikut :

1. Agar pemasaran produk melalui internet dapat meningkat diperlukan usaha-usaha peningkatan persepsi positip konsumen terhadap kemudahan berbelanja, kenyamanan Effisiensi dengan cara peningkatan promosi, disamping peningkatan keamanan serta sistem pembayarannya.

2. Persepsi prilaku konsumen terhadap pembelian produk melalui internet menunjukkan persepsi positif, disini dapat disarankan agar dalam pemasaran di dunia maya yang mengutamakan unsure kepercayaan perlu menjaga kualitas produk dan kestabilan harga sehingga banyak konsumen beralih membeli produk melalui internet. 